\title{
Analysis of the Arthroscopically Diagnosed Soft-Tissue Injuries Associated With the Distal Radius Fractures
}

\author{
Katerina Kasapinova*, Viktor Kamiloski \\ Department of Traumatology, University Surgery Clinic “St. Naum Ohridski” Skopje, Skopje, Republic of Macedonia
}

\author{
Citation: Kasapinova K, Kamiloski V. Analysis \\ of the Arthroscopically Diagnosed Soft-Tissue \\ Injuries Associated With the Distal Radius \\ Fractures. OA Maced J Med Sci. 2014 Jun 15; \\ 2(2):277-282 \\ http://dx.doi.org/10.3889/oamjms.2014.046 \\ Key words: Distal radius fractures; Wrist \\ arthroscopy; Triangular fibrocartilage complex; \\ soft-tissue lesions; Scapholunate ligament. \\ "Correspondence: Katerina Kasapinova, MD. \\ University Surgery Clinic "Sv.Naum Ohridski" \\ Skopje, 11 Oktomvri 53, 1000 Skopje, Republic \\ of Macedonia. Tel.: +389 2 3235040. E-mail: \\ kasapinovakaterina@yahoo.com \\ Received: 13-Apr-2014; Revised: 15-Apr- \\ 2014; Accepted: 02-Jun-2014; Online first: \\ 05-Jun-2014 \\ Copyright: () 2014 Kasapinova \& Kamiloski. \\ This is an open access article distributed under \\ the is ans of the \\ the terms of the Creative Commons Attribution \\ License, Which permits unrestricted use, \\ distribution, and reproduction in any medium, \\ provided \\ credited. \\ Competing Interests: The authors have \\ declared that no competing interests exist.
}

\begin{abstract}
AIM: The aim of this study was to analyze the frequencies of these soft-tissue injuries and to describe the arthroscopic technique used for their diagnosis.

METHODS: The prospective study included 85 patients with operatively treated distal radius fracture. Wrist arthroscopy was used to identify the associated lesions of triangular fibrocartilage complex (TFCC), scapholunate ligament (SL) and lunitriquetral ligament (LT), extrinsic ligaments, and chondral lesions.

RESULTS: Wrist arthroscopy identified TFCC injury in $72.9 \%$, SL injury in $65.9 \%$, LT injury in $17.7 \%$, extrinsic ligaments in $49.4 \%$ and chondral lesion in $30.6 \%$ of the patients. $87.1 \%$ of the patients had at least one of the major structures injured (TFCC, SL or LT). The presence of the ulnar styloid fractures significantlly correlated with with the associated LT lesion, with the LT lesion type, and with the lesion of both SL and LT ligament. If the distal radius fracture was intraarticular there was no correlation with the finding of any associated soft-tissue lesion.
\end{abstract}

CONCLUSIONS: The frequency of the associated soft-tissue lesions in distal radius fractures is high. Ulnar styloid fracture was identified as risk factor for associated LT lesion, as well as combined lesion of both scapholunate and luntriquetral ligament.

\section{Introduction}

Treatment algorithm of distal radius fractures has evolved substantially over the past decades. Most of the studies that compared different options for treatment of distal radius fractures have not investigated the extent and influence of the associated injuries of the cartilage, the triangular fibrocartilage complex or the intercarpal ligaments. Lately, increased recognition is being given to the assessment and management of the associated softtissue injuries. It is these injuries that are suspected to be the cause of unsatisfactory results in patients with properly restored bony anatomy [1-3]. Overlooking the associated soft-tissue injuries in the past may be owing to the less rigorous assessment of outcome or because prolonged immobilization in cast or external fixation failed to show the soft-tissue deficiencies during the initial aftercare. Current trends in distal radius fracture management include early and more aggressive rehabilitation protocols. In this setting, softtissue injuries become more apparent [3-5].

The diagnosis of soft-tissue wrist injury on plain radiographs can be difficult in absence of gross deformity and even the use of arthrograms, ultrasound and magnetic resonance imaging may fail to demonstrate lesions [6-8], suggesting that direct visualization with use of arthroscopy is the most accurate method [9].

Arthroscopy of the wrist has provided a new and different window into the wrist joint. Indeed, an increasing number of investigative studies in peerreviewed orthopedic journals have confirmed that arthroscopy of the wrist is an accurate diagnostic tool $[1,10,11]$.

The focus of this study was neither on the 
treatment of distal radius fractures nor the treatment of the associated soft-tissue lesions. The aim of this study was to analyze the frequencies of the soft-tissue injuries associated with distal radius fractures and to provide a brief description of the arthroscopic technique used for their diagnosis.

\section{Materials and Methods}

\section{Patients}

This clinical study was designed as prospective randomized study of patients with a distal radius fracture. The study was approved by the Ethical committtee of the Ministry of health of Republic of Macedonia, as well as the Ethical committee of the Medical faculty in Skopje.

Inclusion criteria were: acute distal radius fracture in patients with mature sceleton, age 18-65 years (this excludes the influence of the clinically relevant osteoporosis [12]), operative treatment indicated (regardless of the type of the fixation method used [13]). Exclusion criteria were: fracture in patients with unfused epiphyses, concomitant carpal or hand fractures on the initial radiographs (carpal fracture), neuro-vascular injury. As exclusion criteria the contraindications for the wrist arthroscopy were also considered (local infection, compartment syndrome, positioning problems in vertical traction). 85 patients met the inclusion criteria. The following data were recorded: age, gender, injured side.

\section{Diagnostic wrist arthroscopy}

The arthroscopic examination followed a standardized protocol $[14,15]$. All the operations were performed by the two authors.

Patient was postitioned in supination (general anesthesia), hand in abduction with a use of pneumatic tourniquet. Wrist distraction was achieved with standard mechanism for vertical wrist traction with finger traps. $2.7 \mathrm{~mm}$ arthroscope was used, $30^{\circ}$ angulated. Initialy the arthroscope was introduced through the dorsal 3-4 portal and the joint was lavaged to clear it form haemathoma and fracture debris. Than an aditional radiocarpal portal 6R was created. A small joint shaver was placed through this portal to help clear all the remaining hemathoma, dorsal synovitis and provide a clear view of all joint structures and fracture site that were examined with a probe. Than an inspection of the midcarpal joint was done to evaluate the integrity of the intercarpal ligaments, as well as chondral lesions. Dorsal radial midcarpal (MCR) and ulnar midcarpal (MCU) portals were used.

Intraoperatively, with arthroscopy, systematic inspection of the following soft-tissue structures was done: - triangular fibrocartilage complex (TFCC); - intercarpal ligaments (scapholunate interosseous ligament (SL) and lunotriquetral interosseous ligament (LT)); - extrinsic ligaments (volar and dorsal capsular ligaments); and - chondral surfaces.

The triangular fibrocartilage complex (TFCC) was assessed with a probe, detecting intact surface or tear. To examine the TFCC integrity the "trampoline test" and "hook test" were used [14]. The arthroscopic finding of the TFCC integrity was classified according Palmer's classification system [16]. It divides the TFCC lesions in two categories: traumatic (Class I) and degenerative (Class II). Four types in Class I describe the lesion location: IA (central), IB (ulnar), IC (distal) and ID (radial).

The scapholunate interosseous ligament (SL) and lunotriquetral interosseous ligament (LT) were assessed both from the radiocarpal and the midcarpal joint, and the findings were graded with the use of the Geissler arthroscopic classification for the carpal interosseous ligaments $[1,17]$.

The following extrinsic radiocarpal ligaments were probed and if present a tear was noted: volar (radioscaphocapitate, long radiolunate, short radiolunate, ulnolunate and ulnotriquetral) and dorsal ( dorsal radiocarpal).

Direct visuelization of all chondral surfaces during arthroscopy enables correct identification of their lesions. The modified Outerbridge system for classification of cartilaginous lesions was used (Grade I - localized cartilage softening; Grade II - fibrilated articular surfaces; Grade III - thicker flap of cartilage; Grade IV - full-thickness defect of cartilage)[18].

When radiocarpal and/or midcarpal joint arthroscopic inspection was completed, the operative fixation of the distal radius fracture was performed.

\section{Radiographic evaluation}

On the initial x-ray (confirmed with the intraoperative fluoroscopy and arthroscopic exploration) the type and subtype of the fracture was determined according $\mathrm{AO}$ classification of the long bone fractures [19], identifying: type $A, B$ and $C$ and their groups: Type A - extra-articular fracture (A2 simple impacted, A3 comminuted); Type B - partially articular fracture (B1 - radial styloid, B2 - coronal plane, B3 - combined styloid and coronal); Type C complete articular fracture (C1 - simple articular and metaphyseal fracture, C2 - metaphyseal multifragmentary, C3 - articular multifragmentary). The presence of the concomitant ulnar styloid fracture was noted.

\section{Division of the series of patients in groups}

According the arthroscopic findings patients were divided in following study groups: 1) with 
associated TFCC lesion; 2) with intact TFCC; 3) with associated scapholunate lesion; 4) with intact scapholunate ligament; 5) with associated lunotriquetral lesion; 6) with intact lunotriquetral ligament; 7) with injured both scapholunate or lunotriquetral ligaments; 8) with intact both scapholunate or lunotriquetral ligaments; 9) with associated TFCC, as well as scapholunate or lunotriquetral lesion; 10) with associated lesion of at least one of TFCC, scapholunate or lunotriquetral ligament; 11) with intact TFCC, SLIL and LTIL; 12) with associated injury of the extrinsic ligaments; 13) extrinsic ligaments intact; 14) with associated injury of the chondral surfaces (Gr II, III and IV); 15) with chondral surfaces intact or injured Gr. I.

According the radiographic findings patients were divided in following study groups: - extraarticular fractures (Type A, AO classification); - intraarticular fractures (Type B and C, AO classification); associated ulnar styloid fracture; - intact ulnar styloid.

\section{Statistical analysis}

Results obtained from this study were analyzed with the statistical software package SPSS 17 for Windows. Data were presented as mean scores and percentages. Spearman's correlation was used to test the statistical correlation of the type of the fracture (extra- or intraarticular fracture), as well as presence of concomitant ulnar styloid fracture with the presence of the associated soft-tissue lesions. $p<0.05$ was considered significant.

\section{Results}

Characteristics of the patients evaluated in this study are shown in Table 1.

Table 1: Characteristics of the evaluated patients.

\begin{tabular}{lc}
\hline & All $(\mathrm{n}=85)$ \\
\hline Age & $51.06(16-65)$ \\
Gender (F/M) & $(62.3 \% / 37.7 \%)$ \\
Injured side (R/L) & $36 / 49$ \\
AO classification & \\
A2 & 4 \\
A3 & 20 \\
B1 & 0 \\
B2 & 2 \\
B3 & 2 \\
C1 & 14 \\
C2 & 16 \\
C3 & 27 \\
Intra-articular fracture & $61(71.8 \%)$ \\
Yes & $24(28.2 \%)$ \\
No & $55(64.7 \%)$ \\
Ulnar fracture & $30(35.3 \%)$ \\
Yes & 10 \\
No & 33 \\
Fixation method & 20 \\
AAPP & 21 \\
External fixation & 1 \\
ORIF volar locked plate & \\
ORIF conventional plate & \\
ORIF dorsal locked plate $\quad$ AAPP- Arthroscopy assisted percutaneous pinning \\
\multicolumn{2}{c}{ ORIF - Open reduction and internal fixation } \\
&
\end{tabular}

The arthroscopic exploration identified TFCC lesion in 62 patients $(72.9 \%)$, in 23 patients $(27.1 \%)$ TFCC was intact. According Palmer's classification in
9 patients central TFCC perforation was diagnosed (Type IA); in 12 patients ulnar lesion (IB); in 6 patient's distal lesion of the ulnolunate and/or ulnotriquetral ligament (IC), and radial TFCC avulsion in 35 patients (ID). The frequencies of all other soft-tissue lesions arthroscopically diagnosed are presented in Table 2.

Table 2: Frequency of soft-tissue injuries associated with distal radius fractures.

\begin{tabular}{|c|c|c|c|}
\hline & $\begin{array}{l}\text { INTACT } \\
\mathrm{n}(\%)\end{array}$ & $\begin{array}{l}\text { INJURED } \\
\mathrm{n}(\%)\end{array}$ & \\
\hline TFCC & $23(27.1)$ & $62(72.9)$ & $\begin{array}{l}\text { IA - } 9(14.5) \\
\text { IB - } 12(19.3) \\
\text { IC - } 6(9.7) \\
\text { ID - } 35(56.5)\end{array}$ \\
\hline$\overline{S L}$ & $29(34.1)$ & $56(65.9)$ & $\begin{array}{l}\text { Gr. I - } 20(35.7) \\
\text { Gr. II - } 29(51.8) \\
\text { Gr. III - } 5(8.9) \\
\text { Gr. IV - } 2(3.6)\end{array}$ \\
\hline LT & $70(82.3)$ & $15(17.7)$ & $\begin{array}{l}\text { Gr. I - } 6(40.0) \\
\text { Gr. II - } 4(26.7) \\
\text { Gr. III - } 4(26.7) \\
\text { Gr. IV - } 1(6.7)\end{array}$ \\
\hline Both SL \& LT & $28(32.9)$ & $14(16.5)$ & \\
\hline One of TFCC or SL or LT & $74(87.1)$ & $11(12.9)$ & \\
\hline TFCC \& SL or LT & & $45(52.9)$ & \\
\hline Extrinsic lig. & $43(50.6)$ & $42(49.4)$ & \\
\hline $\begin{array}{l}\text { Chondral surfaces } \\
(\geq G \text { r.II) }\end{array}$ & 59 (69.4) & $26(30.6)$ & \\
\hline
\end{tabular}

The association of the presence of concomitant ulnar styloid fracture with the arthroscopic finding of associated soft-tissue lesion is shown in the Table 3. This table also presents the frequencies of the associated sof-tissue lession in intraarticular and extraarticular fractures separately.

Table 3: Associated soft-tissue injuries distribution in distal radius fractures with/without ulnar styloid fracture and in intra/extraarticular distal radius fractures.

\begin{tabular}{|c|c|c|c|c|c|c|c|c|c|c|c|c|}
\hline & \multicolumn{2}{|c|}{ TFCC } & \multicolumn{2}{|l|}{ SL } & \multicolumn{2}{|l|}{ LT } & \multirow{2}{*}{$\begin{array}{l}\begin{array}{l}\text { SL } \\
\text { LT } \\
(+)\end{array} \\
\end{array}$} & \multirow{2}{*}{$\begin{array}{l}\text { and } \\
(-) \\
\end{array}$} & \multicolumn{2}{|c|}{$\begin{array}{l}\text { EXTRINSIC } \\
\text { LIG. }\end{array}$} & \multicolumn{2}{|c|}{$\begin{array}{l}\text { CHONDRAL } \\
\text { SURF. }\end{array}$} \\
\hline & $(+)$ & $(-)$ & $(+)$ & $(-)$ & $(+)$ & $(-)$ & & & $\begin{array}{l}(+) \\
\text { a }\end{array}$ & $(-)$ & $\begin{array}{l}(+) \\
\text { (a) }\end{array}$ & $(-)$ \\
\hline $\begin{array}{l}\text { Ulnar styloid } \\
\text { fracture (55) }\end{array}$ & 43 & 12 & 35 & 20 & 5 & 50 & 4 & 51 & 25 & 30 & 18 & 37 \\
\hline $\begin{array}{l}\text { Ulnar styloid } \\
\text { intact (30) }\end{array}$ & 19 & 11 & 21 & 9 & 10 & 20 & 10 & 20 & 17 & 13 & 8 & 22 \\
\hline $\begin{array}{l}\text { Intraarticular } \\
\text { fracture (61) }\end{array}$ & 45 & 16 & 42 & 19 & 13 & 48 & 12 & 49 & 31 & 30 & 18 & 43 \\
\hline $\begin{array}{l}\text { Extraarticular } \\
\text { fracture (24) }\end{array}$ & 17 & 7 & 14 & 10 & 22 & 2 & 2 & 22 & 11 & 13 & 8 & 16 \\
\hline $\begin{array}{l}\text { TFCC - triangu } \\
\text { SL - scapholun } \\
\text { LT - lunotrique }\end{array}$ & & & & & & & & intact & & & & \\
\hline
\end{tabular}

The correlation of the type of the fracture expressed as intraarticular or extraarticular fracture with the pressence of the associated soft-tissue lesions, as well as the correlation of the presence of ulnar styloid fracture is shown in Table 4. The statistical analyzes found statistically significant correlation of the presence of the ulnar styloid fracture with the associated lesion of lunotriquetral ligament, with the lunotriquetral ligament lesion type, and with the presence of associated lesion of both scapholunate and lunotriquetral ligament. If the distal radius fracture was intraarticular there was no correlation with the finding of any associated softtissue lesion.

Figures 1-6 show arthroscopic view of some of our patients with the associated soft-tissue lesions. 


\section{Discussion}

The present study demonstrated that more than $70 \%$ of the patients with distal radius fracture would sustain a TFCC injury as well, and around 65\% an injury of the scapholunate ligament. If we add here around $50 \%$ with an extrinsic ligaments injury and around $30 \%$ with chondral lesion, than the magnitude of the problem of the associated soft-tissue lesions becomes more apparent. Only $13 \%$ of the patients in our study had all the major structures (TFCC, SL and LT) intact.

Table 4: Spearman's correlation of the type of the distal radius fracture (intra/extraarticular) and the presence of the ulnar styloid fracture with the presence of associated soft-tissue lesion.

\begin{tabular}{lll}
\hline & correl. coeff. & $\mathrm{p}$ \\
\hline INTRAARTICULAR FRACTURE & & \\
TFCC lesion present & 0.030 & 0.787 \\
TFCC lesion type (IA-ID) & 0.010 & 0.927 \\
SL lesion present & 0.100 & 0.363 \\
SL lesion type (0-4) & 0.071 & 0.518 \\
LT lesion present & 0.153 & 0.161 \\
LT lesion type (0-4) & 0.151 & 0.168 \\
Both SL and LT lesion present & 0.138 & 0.209 \\
Extrinsic lig.injured & 0.045 & 0.683 \\
Chondral lesion ( $\geq$ Gr.II) & -0.037 & 0.734 \\
ULNAR STYLOID FRACTURE & & \\
TFCC lesion present & 0.160 & 0.144 \\
TFCC lesion type (IA-ID) & 0.090 & 0.412 \\
SL lesion present & -0.064 & 0.560 \\
SL lesion type (0-4) & -0.046 & 0.674 \\
LT lesion present & -0.304 & 0.005 \\
LT lesion type (0-4) & -0.321 & $\mathbf{0 . 0 0 3}$ \\
Both SL and LT lesion present & -0.336 & $\mathbf{0 . 0 0 2}$ \\
Extrinsic lig.injured & -0.107 & $\mathbf{0 . 3 2 9}$ \\
Chondral lesion ( $\geq$ Gr.II) & 0.063 & 0.568 \\
\hline
\end{tabular}

TFCC-triangular fibrocartilage complex.

SL-scapholunate ligament.

LT-lunotriquetral ligament.

A point of concern arises from the observation if the fractures of the distal radius are common [20] and these associated soft-tissue lesions are frequent and demonstrably painful, than why the problem of soft-tissue was not observed in the past, and not enough clinical studies paid attention to it? Maybe the explanation for this is the fact that the residual pain was explained as normal during the fracture healing.

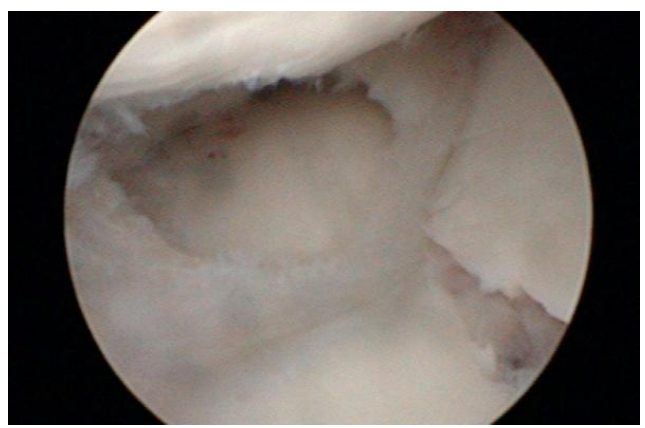

Figure 1: Central TFCC lesion and distal radius fracture extending in the sigmoid notch.

On the other hand, in the past, prolonged immobilization as conservative method of treatment and external fixation that provided immobilization as well, were dominant methods of treatment of the fractures of the distal radius. The speculation is that this immobilization provided adequate treatment for some of the soft-tissue lesions. Today, the modern trends for stable internal fixation with early aggressive mobilization gave way for the soft-tissue lesion to be more apparent, resulting in clinical instability and pain. This may be the reason why the studies that

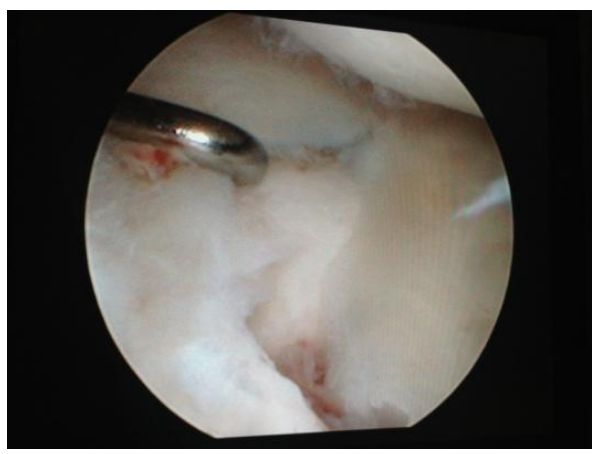

Figure 2: Radial TFCC tear (Type ID).

compared external fixation and percutaneous techniques, with the internal fixation with locked implants, failed to demonstrate significantly better outcome for the newer techniques [21-24]. In order to improve our understanding of the problem of residual pain and disability in distal radius fractures, attention to the soft-tissue injuries has to be paid.

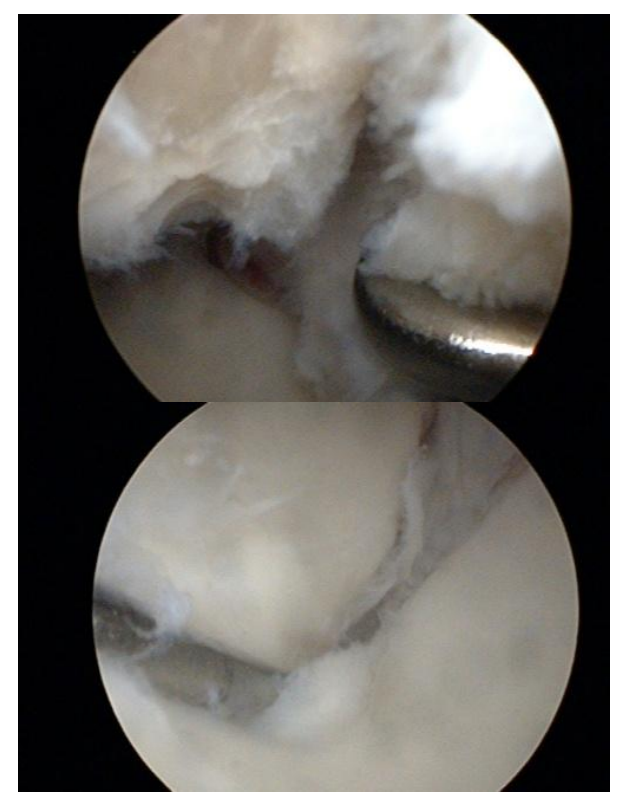

Figure 3: Scapholunate ligament tear seen from the midcarpal joint and from the radiocarpal joint.

I both intra- and extrarticular distal radius fractures tears of the TFCC and intercarpal ligaments were found. These injuries were present not only in severely comminuted and displaced intrarticular fractures, but also in minimally displaced extraarticular fractures.

The studies of Geissler [1], Mehta [25] and Hanker [26] examined only intraarticular fractures. According the study of Richards [11] and Ogawa [27] 
no significant difference existed between extra- and intraarticular fractures with respect to the frequencies of the ligamentous injuries. On contrary, the study of Forward [8] identified intraarticular fracture as an important risk factor for scapholunate ligament injury. Our study did not demonstrate any significant correlation between the presence of intraarticular fracture and the presence of any associated softtissue lesion.

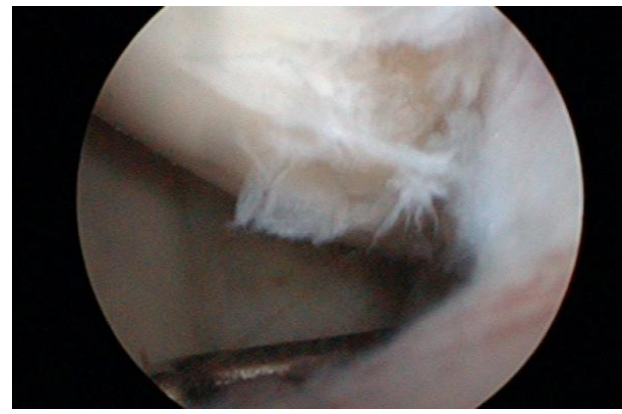

Figure 4: Lunotriquetral ligament tear seen form the radiocarpal joint.

The study of Richards et al. [11] found no correlation between ulnar styloid fractures and the TFCC injuries. Some other studies confirmed the same $[9,10,28]$.

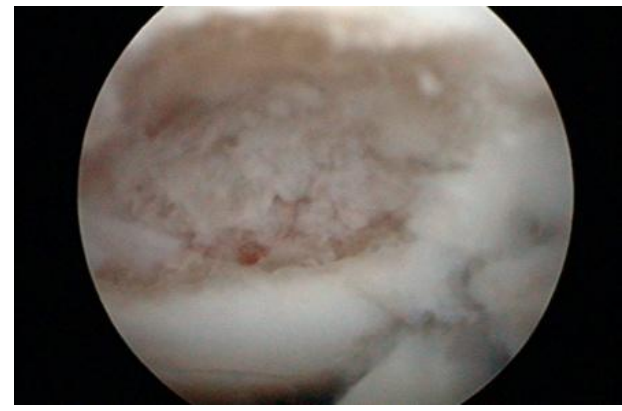

Figure 5: Lunate chondral defect Gr. IV.

The present study showed that there was no correlation between the ulnar styloid fracture and the associated TFCC injury. There was no correlation with the presence of chondral lesion, extrinsic ligaments lesion and isolated scapholunate lesion as well. But our study found significant correlation with the presence of the lunotriquetral ligament lesion, with its type, and with the presence of associated lesion of both scapholunate and lunotriquetral ligament. This finding could be explained with the proximity of the ulnar styloid and the lunotriquetral ligament and the transfer of the energy of the injury. The concomitant ulnar styloid fracture was identified as a predictor for lunotriquetral ligament injury.

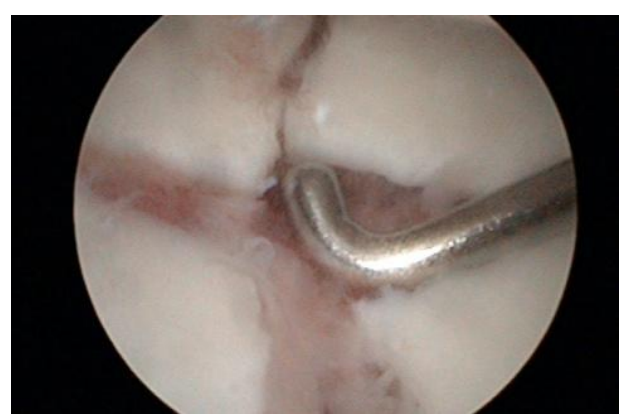

Figure 6: Intraarticular distal radius fracture-arthroscopic view.

The results of this study confirm that the arthroscopy was a valuable and sensitive method for determining the prevalence and severity of the softtissue lesions associated with distal radius fractures that were not detectable on standard radiographs of the wrist. Accurate restoration of the bony anatomy is essential to minimize complications [2, 29], but softtissue injuries are recognized as a significant source of associated problems [3-5].

In theory the traumatic TFCC lesions type IA and ID require debridement to reduce pain, and type IB should be repaired to prevent DRUJ instability [14]. Our study identified a total of 56 patients (65.8\%) with either type IA, IB or ID TFCC lesion. In Gr.III and Gr.IV scapholunate and lunotriquetral lesions, transfixion is indicated [14]. In our study there were 7 patients (8.2\%) with this type of SL injury and 5 (5.8\%) with LT respectively. This shows that the frequency of soft-tissue lesions that required additional treatment was not negligible. Arthroscopy prevented these considerable percentages of cases being overlooked. That is why wrist arthroscopy is useful and should be mastered by surgeons treating distal radius fractures. The results of this study and similar published studies suggest that arthroscopy should be incorporated more frequently into the treatment algorithm for distal radial fractures.

The ligamentous injuries may lead to carpal instability, it may be easier to treat them at the time of the initial presentation, and doing so has been shown to lead to improved outcomes [1, 30, 31]. However, the natural history and clinical importance of these ligament injuries associated with distal radius fractures are not yet known and understood. In may not be necessary to treat all these lesions as some studies recommended [17], but persistent symptoms and instability resulting from these injuries. There is a need for future randomized studies to investigate the correlation of these soft-tissue injuries with the outcome of the distal radius fractures.

In conclusion, this study demonstrated high frequency of the associated soft-tissue lesions in distal radius fractures. The study identified the following important risk factors for associated softtissue lesion in distal radius fractures: (1) ulnar styloid fracture for associated lunotriquetral ligament lesion (2) ulnar styloid fracture for associated combined lesion of both scapholunate and luntriquetral ligament. 
There was no difference between extra- and intraarticular fractures with respect to the frequencies of the soft-tissue injuries.

These soft-tissue lesions may represent an important confounding factor in the outcome of the distal radius fractures. Wrist arthroscopy has proven to be an accurate diagnostic and therapeutic tool for these associated lesions. We recommend that the associated soft-tissue lesions be considered when treating the fractures of the distal radius and wrist arthroscopy be incorporated into the treatment algorithm for distal radial fractures.

\section{References}

1. Geissler WB, Freeland AE, Savoi FH, et al. Intracarpal soft-tissue lesions associated with an intraarticular fracture of the distal end of the radius. J Bone Joint Surg Am. 1996;78:357-365.

2. Fernandez DL. Should anatomic reduction be pursued in distal radial fractures? J Hand Surg [Br]. 2000;25: 523-527.

3. Smith DW, Henry MH. Comprehensive management of softtissue injuries associated with distal radius fractures. Journal of the American Society for Surgery of the Hand. 2002;2:153-164.

4. Shin AY, Deitch MA, Sachar K, Boyer MI. Ulnar-sided wrist pain J Bone Joint Surg Am. 2004; 86: 1560-1574.

5. Lozano-Calderon SA, Souer S, Mudgal C, Jupiter JB, Ring D. Wrist mobilization following volar plate fixation of fractures of the distal part of the radius. J Bone Joint Surg Am. 2008;90:1297-1304.

6. Weiss AP, Akelman E, Lambiase R. Comparison of findings of triple-injection cinearthrography of the wrist with those of arthroscopy. J Bone Joint Surg Am. 1996; 78:348-356.

7. Dao KD, Solomon DJ, Shin AY, Puckett ML. The efficacy of ultrasound in the evaluation of dynamic scapholunate ligamentous instability. J Bone Joint Surg Am. 2004;86:1473-1478.

8. Forward DP, Lindau TR, Melson DS. Intercarpal ligament injuries associated with fractures of the distal part of the radius. J Bone Joint Surg Am. 2007;89:2334-2340.

9. Lindau T, Arner M, Hagberg L. Intraarticular lesions in distal fractures of the radius in young adults. A descriptive arthroscopic study in 50 patients. J Hand Surg [Br]. 1997;22:638-643.

10. Lindau T, Adlercreutz $C$, Aspenberg $P$. Peripheral tears of the triangular fibrocartilage complex cause distal radioulnar joint instability after distal radial fractures. J Hand Surg [Am] 2000;25:464-468.

11. Richards RS, Bennett JD, Roth JH, Milne K. Arthroscopic diagnosis of intra-articular soft tissue injuries associated with distal radial fractures. J Hand Surg [Am]. 1997;22:772-776.

12. Poole KE, Compston JE. Osteoporosis and its management, BMJ. 2006; 333:1251-1256.

13. Lichtman DM, Bindra RR, Boyer Ml et as. American academy of orthopaedic surgeons clinical practice guideline on the treatment of distal radius fracture. J Bone Joint Surg Am. 2011;93:775-778.

14. DelPinal F, Mathoulin C, Luchetti R. Arthroscopic management of distal radius ractures. Berlin Heidelberg: Springer Verlag; 2010.

15. Geissler WB. Wrist arthroscopy. New York: Springer Science Business Media; 2005.

16. Palmer AK. Triangular fibrocartilage complex lesions: a classification. J Hand Surg [Am].1989;14:594-606.

17, Geissler WB. Intra-articular distal radius fractures: the role of arthroscopy? Hand Clin. 2005;21:407-416.
18. Outerbridge RE. The etiology of chondromalacia patellae. $J$ Bone Joint Surg Br. 1961;43:752-757.

19. Muller ME, Nazarian $S$, Koch $P$, et al. The Comprehensive Classification of Fractures of Long Bones. Berlin Heidelberg New York: Springer-Verlag; 1991.

20. Larsen CF, Lauritsen J. Epidemiology of acute wrist trauma. Int J Epidemiol. 1993;22:911-916.

21. Walenkamp MMJ, Bentohami A, Beerekamp MSH, Peters RW, van der Heiden R, Goslings JC, Schep NWL. Functional outcome in patients with unstable distal radius fractures, volar locking plate versus external fixation: a meta-analysis. Strat Traum Limb Recon. 2013;8:67-75

22. Kasapinova K, Kamiloski V. Open reduction and internal fixation versus external fixation and/or Kirschner wires for distal radius fractures. A systematic review. Contributions. Sec. Med. Sci. 2014;35(1):225-236

23. Hull P, Baraza N, Gohil M, Whalley H, Mauffrey C, Brewster M, Costa ML. Volar locked plates versus K-wire fixation of dorsally displaced distal radius fractures - a functional outcome study. J Trauma. 2011;70:E125-E128.

24. Wilcke MK, Abbaszadegan $\mathrm{H}$, Adolphson PY. Wrist function recovers more rapidly after volar locked plating than after external fixation but the outcomes are similar after 1 year. Acta Orthop. 2011;82:76-81.

25. Mehta JA, Bain GI, Heptinstall RJ. Anatomical reduction of intraarticular fractures of the distal radius (an arthroscopically-assisted approach). J Bone Joint Surg Br. 2000;82:79-86.

26. Hanker GJ. Radius fractures in the athlete. Clin Sports Med. 2001;20:189-201.

27. Ogawa T, Tanaka T, Yanai T, Kumagai H, Ockiai N. Analysis of soft tissue injuries associated with distal radius fractures. BMC Sports Science, Medicine and Rehabilitation. 2013;5:19.

28. Lindau T. Treatment of injuries to the ulnar side of the wrist occurring with distal radial fractures. Hand Clin. 2005;21:417-425.

29. Knirk JL, Jupiter JB. Intraarticular fractures of the distal end of the radius in young adults. J Bone Joint Surg Am. 1986;68:647-659.

30. Whipple TL. The role of arthroscopy in the treatment of scapholunate instability. Hand Clin. 1995;11:37-40.

31. Peicha G, Seibert F, Fellinger M, et al. Midterm results of arthroscopic treatment of scapholunate ligament lesions associated with intra-articular distal radius fractures. Knee Surg Sports Traumatol Arthrosc. 1999;7:327-333. 